\title{
How Are Black Learners Positioned in Mathematics Classrooms? What Do We Know and What Do We Need to Know?
}

\author{
Charles Eugene Wilkes II and Deborah Loewenberg Ball \\ University of Michigan, Ann Arbor
}

\begin{abstract}
Authors note
This manuscript is based upon work supported by the Mindset Scholars Network's Inclusive Mathematics Environments Early Career Fellowship, with funding provided by a grant from the Bill \& Melinda Gates Foundation. The content is solely the responsibility of the authors and does not necessarily represent the views of the Mindset Scholars Network or the Bill \& Melinda Gates Foundation.

We thank Shanette Porter, Tanner LeBaron Wallace, Maisie L. Gholson, Luis A. Leyva, and for their support and feedback throughout the writing process. Additionally, we thank Ebony Perouse-Harvey for her comments on later drafts of this manuscript.

Correspondence concerning this working paper should be addressed to Charles Eugene Wilkes II, University of Michigan, Ann Arbor; cwilkes@umich.edu.
\end{abstract}




\begin{abstract}
The proliferation of studies that focus on Black children in the last 20 years has been critical in nuancing the mathematical experiences of Black learners. While this research has provided evidence of the existence of successful Black learners of mathematics and established the different mechanisms that serve as barriers to their success, we know less about what happens in classrooms. Specifically, how are Black learners experiencing mathematics moment-tomoment or, over time. In this paper, we synthesize literature on the positioning of Black learners in mathematics classrooms. Focusing on this topic allows for more understanding on how Black learners are positioned and by whom. Leveraging intersectionality as a tool and focusing on the interpersonal and cultural domains of power, provides some understanding of why Black learners are positioned in particular ways. Findings suggest that Black learners are positioned in both productive and unproductive ways by their peers and teachers. Additionally, these positions are connected to the multiple identities of students and teachers, and how they intersect with issues of power, intersectionality. Implications of this synthesis include considerations for how teachers position students implicitly and explicitly, development of policy that requires professional development around intersectionality and training for teachers to improve their practice. We conclude by recommending that future research use intersectionality theory to uncover inequities that occur during mathematics instruction across grade levels, but particularly in middle school grades.
\end{abstract}

Keywords: positioning, intersectionality, Black, mathematics classrooms, identity 


\section{How Are Black Learners Positioned in Mathematics Classrooms? What Do We Know and What Do We Need to Know?}

Introduction

The proliferation of studies that focus on Black children in mathematics the last two decades has extended what we know about the teaching and learning of Black children in mathematics. These studies have described how systems at the macro, meso, and micro-level contribute to the inequities that Black learners experience in mathematics. Additionally, studies have highlighted that despite the inequities they are likely to face, some Black learners achieve success in mathematics in the form of resilience and persistence, as well as in traditional notions of success, which includes grades and test scores (Martin, 2009; Martin and Leonard, 2013; Berry and Thunder, 2015).

These studies not only provided key insights into the experiences of Black learners, they also made key contributions to understanding the significance of identity and identity development for Black learners in mathematics. Often, scholars that study identity in mathematics education research use the following four theories: poststrucutral theory, narrative theory, psychoanalytic theory, and positioning theory (Langer-Osuna and Esmonde, 2017). Poststructural theory examines how broader discourses (e.g. messages and narratives) impact the type of positioning individuals have (e.g. enabled or constrained) and how individuals identify with them. For example, it is common to hear that Asians are good at math, and Black students are not; using poststructural theory we might consider how Black mathematics learners come to understand and process these discourses. Narrative theory focuses on the stories that are generated by individuals describing their experiences across social settings. An example of this approach would be conducting interviews to understand Black learners' experiences in $\mathrm{K}$ 12, post-secondary, or both. Psychoanalytic theory considers the role of unconscious desires and fears and how they serve as coping mechanisms for that identity development as a coping mechanism. Positioning theory posits that individuals are positioned based upon the interactions 
they have with others and claims that are made in settings. Although each theory takes a different approach to identity, they all highlight the importance of interactions within and outside the classroom environment that has implications for students' mathematics identities and subsequently their learning, however for this synthesis we focus on positioning, which includes positioning theory.

Positioning theory focuses on how interactions afford and constrain different identities that may be taken up, modified, or resisted. Some researchers have examined this at a macrolevel (Nasir and Shah, 2013, Shah, 2013, Stinson, 2008), while others have focused on this at the micro-level (Bishop, 2008, Turner et al, 2010, Wood, 2013). Collectively this research has illuminated the importance of the interactions that take place in classrooms often incorporate issues of power, agency, and influence, which shape students' identities. This research has been valuable by providing more detail and nuance about the experience of learners in mathematics classrooms. This work is particularly important for Black learners generally and Black girls specifically, who often have had their identities (mis)taken or rendered invisible (Gholson \& Wilkes, 2017). A number of scholars have begun to focus on how learners are positioned in classrooms to combat deficit-based discourses. Using positioning, provides a finer grain size to examine and understand how Black learners position themselves and are positioned by their peers, and teachers during mathematics instruction. Positioning theory as typically used in mathematics education normally draws upon video recordings of classroom interaction and interviews over extended periods of time. This type of data is particularly useful because it provides detail about the positioning of learners. These data are also useful because positioning at least as outlined by the theory calls for the idea of storyline. The storyline is helpful to contextualize the positioning. It is important to note that positioning theory is interpretive and that not all studies will account for the perspective of the individuals being positioned or how individuals are positioning others. Nevertheless, it still highlights with rigor a plausible interpretation of how students may be positioned. Methodologically it is useful as it 
brings into place agency and power. Agency could be seen from the individual being positioned. You also see power and influence come into play as individuals are positioned. Thus, positioning does not occur in a vacuum, but also is connected to ideas of power.

The purpose of this synthesis is to look across a collection of positioning studies, that focuses on Black learners or classrooms with primarily Black learners, and the interactions between their peers and teachers, to understand how Black learners are positioned in mathematics classrooms. Although, there exist literature that describes interactions that take place during classroom instruction, until this point there has been limited research that extrapolates how these interactions mediate the teaching and learning that takes place in classrooms for Black learners specifically and the implications of this work for policy, research, and practice. In investigating the interactions and positioning of Black learners, we provide insights to productive and unproductive positionings that occur for Black learners during mathematics instruction. By productive we mean the types of positioning that one would associate as good or positive for a learner. For example, positioning a learner as an explainer or as questioner are two examples that are good for learners to do. Additionally, by unproductive we mean positionings that could neither be helpful or harmful, as well as positionings that are problematic for the learner. For example, positioning a Black learner as someone as the model student because they follow the teacher's directions may not be helpful or harmful, whereas positioning a student as competent at the expense of others could be problematic.

\section{Search}

\section{Methods}

We set out to survey all of the literature on positioning for Black learners in mathematics education. By positioning we mean the interactions that take place among individuals that are connected to how students are or might be positioned. Typically, studies that have focused on positioning draw upon positioning theory as outlined in the seminal work by Davies and Harre 
(1990). They define two key terms, position and subject position in their work. They define position as

the discursive process whereby selves are located in conversations as observably and subjectively coherent participants in jointly produced story lines. There can be interactive positioning in which what one person says positions another. And there can be reflexive positioning in which one positions oneself (p. 48).

Also, they define subject position as

A subject position incorporates both a conceptual repertoire and a location for persons within the structure of rights for those that use that repertoire. Once having taken up a particular position as one's own, a person inevitably sees the world from the vantage point of that position and in terms of the particular images, metaphors, storylines and concepts which are made relevant within the particular discursive practice in which they are positioned. At least a possibility of notional choice is inevitably involved because there are many and contradictory discursive practices that each person could engage in (Davies and Harre, 1990, p. 46).

Although these two types of positions are common, it is important to note that we also consider definitions that are broader that is outlined by Davies and Harre (1990).

To survey the literature related to the positioning of Black learners, we generated a set of search terms to identify potential articles to review. We used three databases, EBSCO, ERIC, and ProQuest. In these databases I used the terms "position*", "Black" or "African American", and "math*". I used * for the terms position and math to capture different forms of those base words. For example, using "position*" would include words such as positioning or positions. Similarly using "math*" include mathematics and maths. In addition to using these terms we used the "AND" operator, as well as the "OR" operator. Using these terms in conjunction with the operators, afforded me the opportunity to identify studies that focus on positioning and Black or African American learners in mathematics which may include studies within or outside of mathematics education. I use the terms "Black" and "African American" interchangeably to account for studies that use African American or Black. In addition, articles recommended by 
experts on the topic of identities, positioning, and Black learners' experiences in mathematics were included within the initial search (Gough, 2018).

\section{Inclusion and exclusion criterion}

In generating our final dataset, we used five criteria to include and exclude studies in the synthesis. The first inclusion criterion is the article must be peer-reviewed. Second, all articles had to take place in the U.S. The third criterion is the articles had to be published between 2000 -2020 . We chose this range due to the shift in mathematics education research often called the social turn (Lerman, 2000), which marks when researchers began to incorporate more social theories to investigate phenomena. This point is important because positioning studies (e.g. studies that use positioning theory and studies that do not) are likely to occur during this period. Positioning tends to focus on the different social aspects and their meanings to understand in our case, the teaching and learning of mathematics. Additionally, during this period, policies such as, No Child Left Behind (NCLB), other "turns", sociopolitical turn (Gutiérrez, 2013), and movements, Common Core State Standards (CCSS), increased the likelihood that research would focus on specific racial groups, namely Black students, and the impact of different factors that affect their mathematical experiences. Fourth, because the synthesis was focused on Black learners, I included articles that focused on this group. This meant studies centered in predominantly Black classrooms or focused on Black children. Fifth, articles that used the terms which include position, positioned, or positioning and included Black children were included in the synthesis. Although, the goal of the synthesis was to focus on studies that provided moment-to-moment interactions, other studies were included that did not include moment-tomoment interactions but focused on positioning. I emphasize moment-to-moment interactions because they are likely to provide the details necessary to understand what occurs in classrooms and how. For this study, understanding what actually occurs in classrooms provides us the opportunity to see the nature of the interactions that take during instruction among 
teacher and students, which have implications for how we might consider designing learning environments to ensure the likelihood of quality mathematics instruction. Refer to table 1 for the studies that were included in this synthesis and relevant descriptive information about the studies. 
Table 1

Synthesis dataset

\begin{tabular}{|c|c|c|c|c|c|c|c|c|c|c|c|c|}
\hline 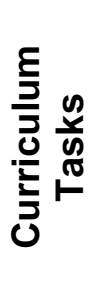 & 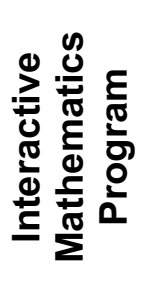 & 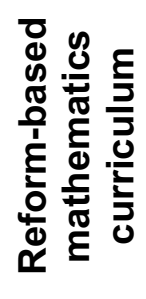 & $\begin{array}{l}\frac{\pi}{0} \\
\frac{0}{0} \\
\frac{0}{0} \\
\frac{d}{\alpha}\end{array}$ & $\begin{array}{l}\frac{\xi}{0} \\
\frac{0}{0} \\
\propto ⿻\end{array}$ & 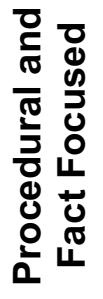 & $\frac{\pi}{z}$ & 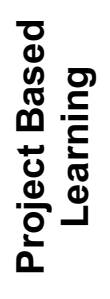 & & $\frac{\varangle}{z}$ & $\frac{\varangle}{z}$ & $\frac{\$}{z}$ & 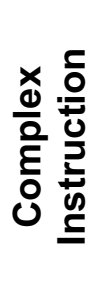 \\
\hline 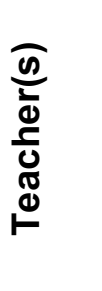 & 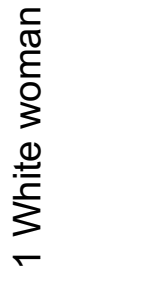 & $\begin{array}{l}\frac{c}{\mathbb{D}} \\
\frac{E}{0} \\
\vdots \\
\vdots \\
\frac{x}{0} \\
\frac{\mathbb{D}}{D} \\
\sigma\end{array}$ & 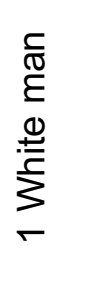 & 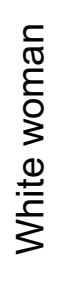 & $\begin{array}{l}\frac{.}{\pi} \\
\varepsilon \\
0 \\
3 \\
\frac{1}{0} \\
\frac{\pi}{\infty}\end{array}$ & 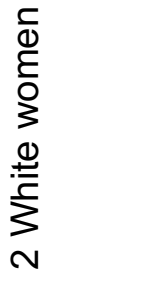 & 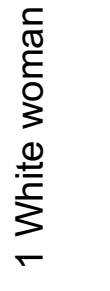 & 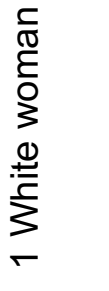 & 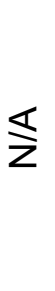 & 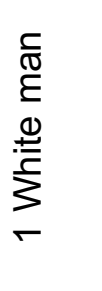 & 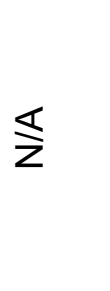 & 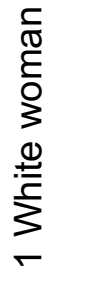 \\
\hline 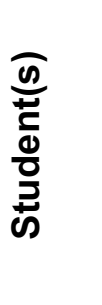 & 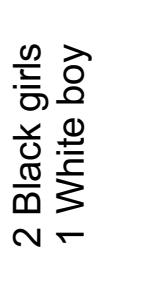 & 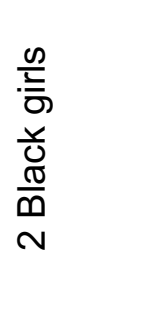 & $\begin{array}{l}0 \\
0 \\
0 \\
\frac{0}{0} \\
\frac{\pi}{m} \\
\dot{v}\end{array}$ & $\frac{1}{z}$ & 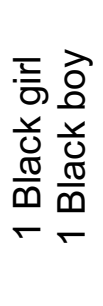 & $\begin{array}{l}. \overline{\bar{J}} \\
\frac{1}{0} \\
\frac{\pi}{0} \\
-\end{array}$ & 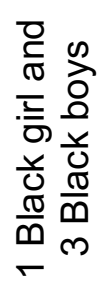 & 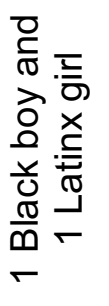 & $\begin{array}{l}0 \\
0 \\
0 \\
\frac{0}{0} \\
\frac{\pi}{0}\end{array}$ & 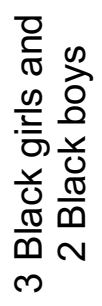 & 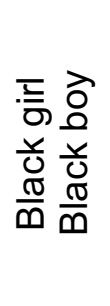 & 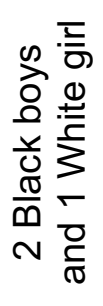 \\
\hline 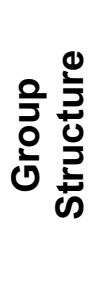 & 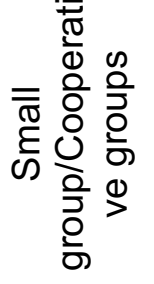 & $\underset{z}{\Sigma}$ & 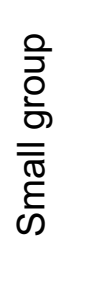 & $\begin{array}{l}\frac{0}{3} \\
\frac{0}{5} \\
\frac{0}{0} \\
\frac{0}{3}\end{array}$ & $\begin{array}{l}\text { 음 } \\
\frac{0}{0} \\
0 \\
\frac{0}{0} \\
\frac{1}{3}\end{array}$ & 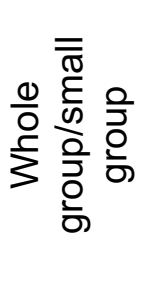 & 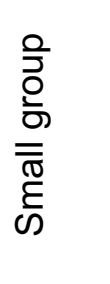 & $\overbrace{0}^{\frac{\pi}{0}}$ & $\widehat{z}$ & 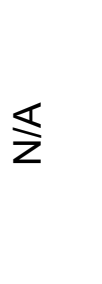 & 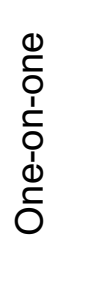 & $\begin{array}{l}\frac{0}{7} \\
\text { ప్ర } \\
\overline{\bar{\sigma}} \\
\stackrel{\bar{E}}{\omega}\end{array}$ \\
\hline
\end{tabular}




\begin{tabular}{|c|c|c|c|c|c|c|c|c|c|c|c|c|}
\hline 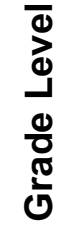 & $\begin{array}{l}\frac{?}{\pi} \\
\frac{0}{0} \\
\overline{0} \\
\dot{0} \\
\infty\end{array}$ & 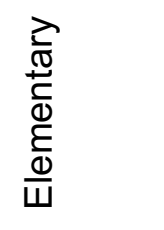 & $\begin{array}{l}\frac{Z}{0} \\
\frac{\pi}{0} \\
\frac{0}{0} \\
0 \\
0 \\
\infty\end{array}$ & $\begin{array}{l}\frac{0}{\frac{0}{0}} \\
\frac{\partial}{\Sigma}\end{array}$ & 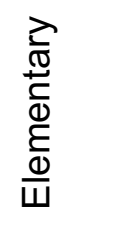 & 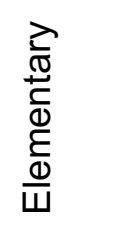 & $\begin{array}{l}\frac{\pi}{0} \\
\frac{\pi}{0} \\
\overline{0} \\
\dot{d} \\
\infty\end{array}$ & 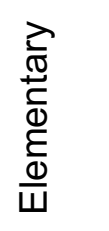 & 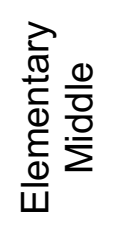 & $\begin{array}{l}\frac{Z}{\pi} \\
\frac{\pi}{0} \\
\overline{0} \\
0 \\
\infty \\
\infty\end{array}$ & 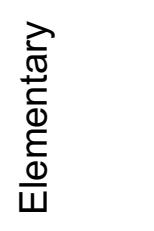 & 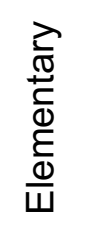 \\
\hline 立 & 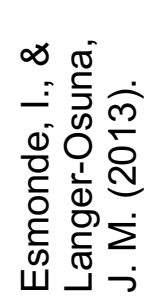 & 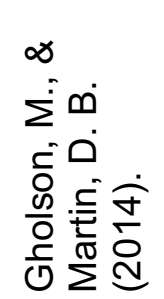 & 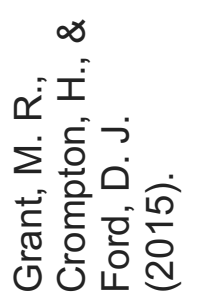 & 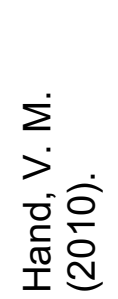 & 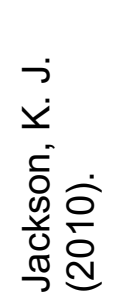 & $\begin{array}{l}\dot{0} \\
\dot{0} \\
0 \\
0 \\
0 \\
0\end{array}$ & 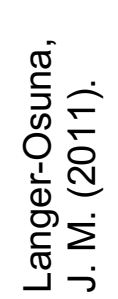 & 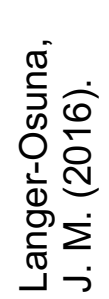 & 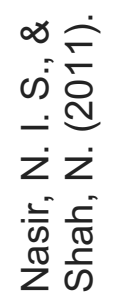 & 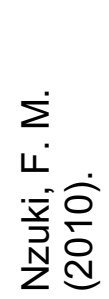 & 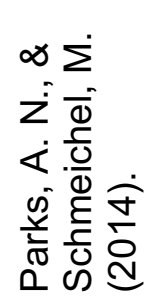 & 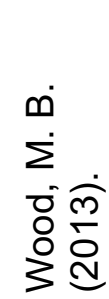 \\
\hline
\end{tabular}




\section{Analytical framework}

Intersectionality coined by Crenshaw (1989) is a term used to describe the multiple social identities that individuals have and how those identities intersect with issues of power. I introduce intersectionality as a complement to studies that focus on positioning. Positioning provides the opportunity to see how Black learners are positioned and by whom. Using intersectionality provides the opportunity to potentially understand why. With this in mind I take up intersectionality as outlined in (Collins \& Blige, 2010). According to Collins and Blige (2010):

Intersectionality as an analytical tool examines how power relations are intertwined and mutually constructing. Race, class, gender, sexuality, dis/ability, ethnicity, nation, religion, and age are categories of analysis, terms that reference important social divisions. But they are also categories that gain meaning from power relations of racism, sexism, heterosexisms, and class exploitation (p. 17)

In using intersectionality as an analytical tool, there are also four domains of power that are used to describe the organization of power: interpersonal, disciplinary, culturally, and structural. The interpersonal domain of power connects power relations to how people are disadvantaged or advantaged within social interactions. The disciplinary domain of power focuses on how rules or policies have differential impact on individuals or are differentially implemented. The cultural domain of power posits ideas matter and attempts to provide explanations for social inequality. The last domain of power, structural, examines how power relations intersect with class gender and race to shape the structure and organization of institutions. (Collins \& Blige, 2010). For the purposes of our synthesis we focus on the interpersonal and cultural domains of power. These two domains are useful in particular as the studies examined in this synthesis focus on the micro-level interactions, which fits particularly well with interpersonal domains of power. The cultural domain of power is relevant due to the focus on making meaning of inequality.

\section{Findings}


In the sections that follow first we define relevant terms, then highlight three findings from conducting the synthesis. In the first section we define productive and unproductive positionings, which allows us to interpret how Black learners were positioned in the studies included in the synthesis. Next we discuss the first finding which elaborates how Black learners are positioned in productive and unproductive ways during mathematics instruction and patterns from these studies. Additionally, we use intersectionality as analytical tool to provide offer additional considerations for the positioning of Black learners in the studies described. In the second section we describe the second finding by providing examples of how the teacher contributes to positioning Black learners in both productive and unproductive ways. To discuss the last finding, we use intersectionality as a tool for studies that explicitly or implicitly focus on the multiple identities of students and teachers that shape how Black learners are positioned in mathematics classrooms. Collectively these findings illustrate how Black learners are positioned, by whom, and other factors that may contribute to those positionings. Additionally, the findings discussed will help us consider the different implications for practice, policy, and research.

\section{Productive and unproductive positioning}

Across the studies in the synthesis one pattern that emerged is students are positioned both in productive and unproductive ways, however these distinctions are complex. By productive positioning we mean a student is positioned as competent by their peers, their teacher, or themselves or positioned as doing something that is important in mathematics. For example, this may include a student being positioned as a mathematical explainer, which is an important skill in mathematics. By unproductive positioning, we mean a student is positioned in problematic ways, such as slow, dumb or incompetent, by their peers, their teacher, or themselves. Unproductive positioning could also be positionings that are not necessarily problematic but are not helpful. An example of this may be positioning a student as fast or good at math, without specifying how or why that is important. It is important to note that these 
positionings are dynamic, meaning that a student can be positioned in productive and unproductive ways in the same moment and in different moments. Looking across the studies in this synthesis several studies highlight how Black learners can be positioned in unproductive ways (Jackson, 2011; Langer-Osuna, 2011; Wood, 2013; Gholson and Martin, 2014). We use three studies to highlight this point, one study that positions a Black boy in unproductive ways and two studies that position Black girls in unproductive ways.

\section{Examples of unproductive positionings.}

One illustration of unproductive positioning can be seen in Wood (2013). In this study the author investigates students' micro-identity development through how they get positioned during small group work in a fourth-grade math class. Specifically, the author examines how Jakeel, a Black boy, is positioned by his teacher, a White woman, his classmate Daren, a Black boy, and another classmate Rebecca, a White girl. Through her analysis Wood (2013) finds during small group work Rebecca often gives Jakeel directives (tells him what to do and write), doesn't allow Jakeel to share his mathematical thinking, and admonishes him when he makes mistakes. Collectively the moves Rebecca makes position Jakeel as mathematically incapable and a menial worker.

Another example of how Black learners are positioned in unproductive ways can be found in Esmonde and Langer-Ousuna (2013). The study investigates how power dynamics impact the opportunities to learn and engage during small group work in a $10^{\text {th }}$ grade math classroom. Using video recordings, the authors describe how students in a focal group position one another in different moments during small group work. The focal group of the analysis was Dawn, a $10^{\text {th }}$ grade Black girl, Riley, a ninth-grade white boy, and Shayenne, a $10^{\text {th }}$ grade Black girl. It is important to note that the classroom in which the study took place used cooperative learning groups, which are groups of students that work together to solve problem-based tasks. With this in mind the author describes one interaction among Riley, Dawn, and Shayenne. While working on a task the authors observed that Riley asked Dawn questions. The questions that he 
asked were questions that he already knew the answer to but asked so that Dawn and

Shayenne would make sense of the problem on their own. Dawn resisted this line of questioning from Riley. She responded by suggesting that Riley answer his own questions and stating that she was not stupid. The line of questions Riley asked imitated questions that the teacher typically asked. One interpretation is Riley was positioned as the mathematical guide or expert. In contrast, Dawn was positioned as powerless and interpreted Riley's leading questions as positioning her as stupid. Considering that White boys are often positioned as smart and Black girls are often positioned as inferior in math, the episode could be considered as reinforcing discourses that are common. Across these two studies we see how two White students position Black students in unproductive ways. Next, I discuss an example of how Black girls position one another in productive ways.

\section{Examples of productive positionings.}

Despite there being examples of unproductive positioning, there are two examples of productive positioning of Black learners. In Wood (2013) we see how a fellow classmate Daren, a Black boy, positions Jakeel as a mathematics student and frames Jakeel as capable of learning. Daren does this work by sharing his solutions and explaining his thinking to Jakeel. Evidence that Jakeel takes up this positioning is seen during small group work when Jakeel asks Darren to explain, listens to feedback, and changes mathematical discourse, indicating that learning took place.

Similarly, In Jackson (2011), we see how Nikki, a Black girl in fifth grade, is positioned as smart and competent through a pedagogical practice, Math Royalty. Math Royalty took place every day at the beginning of class. The purpose of Math Royalty was to increase student's fluency with number facts. To do this work the teacher gave the same five problems to every student in the class on a sheet of paper. The students were expected to answer the questions as fast as they could, then raise their hands to let the teacher know they were done. Once complete, the teacher numbered the students in the order they finished. The student who 
answered the question correctly first were crowned Queen, if they were a girl, and King, if they were a boy. The winner would then go to the front of the class, wear a crown and state, "I rule" and the rest of the class would say "you rule". Nikki frequently finished first in the activity, leading to her being positioned as competent by her peers and having that same status reaffirmed by her teacher. However, over time Nikki continued to win, her peers, namely boy classmates, began to reject her positioning as mathematically competent. As will be discussed later even when Nikki, a Black girl, is positioned in productive ways, the ways in which she is positioned can also be unproductive.

\section{Considerations using intersectionality as an analytic tool for productive and}

\section{unproductive positionings.}

Using intersectionality as a tool offer several considerations for both productive and unproductive positioning of Black learners. First, we address studies position Black learners unproductively. In Wood (2013) we see how Rebecca positions Jakeel as mathematically incapable and as a menial worker. However, what does this positioning mean given that Jakeel is a Black boy and Rebecca is a white girl? Not only does Rebecca position Jakeel this way, but Jakeel takes up this positioning by following her directives. Making meaning of this interaction connects to the cultural domain of power. In this particular case one might consider that Rebecca, a white girl is competent and have power during small group work. Similarly, in Esmonde and Langer-Osuna (2013), we see a parallel instance. For example, Riley, a white ninth grade boy, is positioned as an expert, while Dawn, a $10^{\text {th }}$ grade Black girl is positioned as incompetent. There are multiple things to consider about Riley in this instance, namely that he is in the ninth grade (younger than Dawn), he is White, and he is a boy. Whereas, Dawn is Black, a girl, and in the $10^{\text {th }}$ grade. Collectively thinking about the different identities each have; one can see how Riley has power in this instance. The meaning of this instance could also hint that Riley is smart and the Black girls in the group need his support with the particular task at hand. Although Dawn resists Riley's positioning of her, this instance calls into question the role of the 
students' different identities and how they position each other. Looking across both cases of unproductive positioning it's important to highlight that a White learner positions a Black learner in unproductive ways during small group work and at two different grade levels (elementary and secondary), which provide examples of a potential pattern of Black learners as and their White peers. In particular in one case a white girl positions a Black girl, and, in another case, a White boy positions a Black girl. Both cases embody that White learners are positioned as having power and being seen as competent. Focusing on the studies that positions Black learners in productive ways there is a sharp contrast. For example, in Wood (2013) we see Daren position Jakeel as a mathematics student and capable learner and Jakeel seems to accept this position. In this instance both Daren and Jakeel are Black boys and the message that is conveyed is that they are both competent and can learn from one another. Looking at Jackson (2011), there is a similarity in Nikki, a Black girl, is positioned as competent by her peers who are mostly Black. However, as the school year progresses Black boys in the class begin to discredit Nikki's competence, creating a dynamic of girls versus boys. This case raises the point what does it mean to be competent as a Black boy and Black girl in a mathematics classroom that is majority Black? One meaning that could be made from this case is that the Black boys in the classroom had a perspective on what and who could be seen as competent in class, and Nikki didn't fit that expectation.

Looking across these studies we offer four takeaways. First, Black learners are being positioned in both productive and unproductive ways. Second these positionings are complex, which can be seen, once multiple identities and power is considered. Third, it seems peers play an important role in the positioning of Black learners, particularly during small group work. Fourth, Black learners even when positioned productively, are still at risk to be positioned to be unproductively.

\section{Teachers position Black learners in both unproductive and productive ways}


Black learners get positioned in productive and unproductive ways by different people namely their peers. Although several studies highlight how peers position students, teachers also position students. Few studies in this synthesis describe the teacher and how they might contribute to the positioning of Black learners. Out of the 12 studies only 4 studies addressed teaching, albeit differently. For example, Jones (2003) describes how teachers' beliefs about race, gender, and class narrows what it means to be successful during math class. In contrast, in Jackson (2011) we see how a pedagogical practice, Math Royalty, impacts how students get positioned as smart or competent. Both cases are examples of teaching. The work of teaching plays an important role in how Black learners are positioned in unproductive ways.

Hand (2010) illustrates this example. This study takes place in a low-tracked eighthgrade algebra classroom, with a male teacher with 20 years of teaching experience. In this study the researcher found the ways in which students get positioned is a product of three classroom features: reliance on didactic instruction, polarized participation structure, and weak participation practices. Despite using challenging and rigorous tasks, the teacher's reliance on didactic instruction, meaning the teacher lectures and students are responsible for understanding, undermined teaching and learning for conceptual understanding. This approach meant there were fewer opportunities for students to make sense of the mathematics and are more likely reduced to learning procedural steps. The polarized participation structure hinted at the distinct nature of what was considered productive and unproductive in the class, namely interactions that were social were considered unproductive and interactions related to mathematical behavior was considered as productive. Weak participation practices attend to lack of engagement in class discussions and working on tasks in small groups, for example, which leads to deficit attributions being made about mathematics learners such as being slow or lazy. Each one of these features contributed to how students were positioned individually and collectively. This plays out in the classroom over the course of the academic year through four episodes. Over time the classroom as the author tracks observes how the opportunities 
students are provided such as sharing their ideas, explaining their thinking, and listening to others during the course of year decline; while simultaneously noticing an increase in the frequency of the teacher reprimanding students. The shift in opportunities implicitly and explicitly positioned students as off task and not competent, leading to what the author described as coconstructing opposition.

In contrast to Hand (2010), Wood (2013) represents an example of a teacher positioning students productively. In Wood (2013) the teacher positions Jakeel, a Black boy, as both a mathematical explainer and as mathematically capable during small group work. The teacher does this work by first seeing Jakeel as curious and a sensemaker, which leads to the teacher probing Jakeel's thinking. Jakeel takes up this position by answering the teacher's questions, explaining his thinking, and engaging in other mathematical practices. In this way the teacher is productively positioning Jakeel which contrasts how his peer Rebecca positions him. Specifically, the teacher positions him productively by not giving him directives, engaging with his remarks, and not condemning for errors and any lack of clarity or understanding.

Examining both Hand (2010) and Wood (2010) we consider the relevant domains of power. In Hand (2010) it is important to highlight that the teacher was a White man with over 20 years experiences. The classroom in which he taught was majority students of color. Not to mention that the class was considered a low track. On the interpersonal level, the teacher's stance to see social aspects as unproductive and to reduce challenging tasks to procedural steps have meaning. This meaning could express the need to have control of students, which in this case reduces students' ability to be themselves and exercise agency. It also posits that doing mathematics in this space means in this space and who can do math in this space. Namely that to be seen as competent became very narrow. Contrasting this study is Wood (2010). The teacher is a white woman, and the teacher has the most power in the episode. She has an interaction with Jakeel, a Black boy. In the interaction we get a sense that the teacher values Jakeel's thinking and supports him in making sense of the mathematics. The meaning to 
take away from this, is in this class the teacher's practice seems to support Jakeel in learning and coming to understand through scaffolding. Also, it seems that this is what the teacher does, and the students accept it, in this case Jakeel.

From the four studies that take up teaching, we see that Black learners are positioned in both productive and unproductive ways. In cases where learners are positioned in unproductive ways by the teacher, we see that the opportunities for learning that learners have are often narrowed which leads to unproductive positionings. In the case where a teacher positions a student productively, the teacher first sees the students as a sensemaker and provides opportunities for the learner to explain their thinking.

\section{Examples of studies where intersectionality is described implicitly or explicitly}

The third and last pattern that emerged from the synthesis highlights particular studies that explicitly or implicitly incorporate intersectionality. The studies below highlight both student and teacher examples where intersectionality occurs. Namely the student examples take place in two contexts where the students are mostly Black or all Black. In these studies, we get a sense of heterogeneity in what seems to be a homogenous case. Next, we discuss two examples of studies that take into consideration the identities of a teacher in one case, and a researcher in another that attends to race, class, and gender.

\section{Students.}

In some studies, there was a focus on race, gender, class, or race and gender, but not all three or other social identities. There are at least three examples of where this may be relevant. Langer-Osuna (2011) it provides the opportunity to think about how the intersection of race and gender plays a role in the positioning of Black learners. The study takes place in a project-based $9^{\text {th }}$ grade mathematics classroom. In the study the classroom teacher assigns four projects to each group that are completed over the course of the year. For each project there is one group leader. The purpose of the study was to understand students' trajectories of learning and engagement. The analysis of the study focuses on the interactions of one small 
group composed of Brianna, a Black girl, Kofi, Terrence, and Brandon, Black boys. It is in this group we are able to see how a Black girl and a Black boy are positioned very differently despite having similar discourse patterns. The author found that when Brianna and Kofi were group leaders that made similar moves to other members of the group such as assigning tasks, keeping members on task and offering mathematical help, however members of the group were more likely to not take up Brianna's moves which is evident through students resisting, rejecting, or ignoring Brianna. The other members of the group perceived Brianna's moves as being "bossy", while Kofi's enactment of those same moves positioned Kofi as smart. This finding is interesting considering that both students were considered high achieving. One explanation for this finding is that there are expectations associated with both being black and a girl in this context. Although race wasn't explicitly taken up in this study, one could imagine the role that race played in addition to gender.

Connecting this result to Gholson and Martin (2014), where they explicitly take up both race and gender, we see how the multiple identities impact how Black girls are positioned within mathematics classrooms. The primary focus of the study was to investigate how social networks for Black girls mediate the teaching and learning in a third-grade classroom. The two focal students of the study were Shawna and Mia, two Black girls. Through interviews and observations, the authors argue that the two girls are positioned differently, and these positions are related to both their identities and social networks. For example, Shawna, who is described as a bigger Black girl with short hair, is often positioned as a bully. This positioning is related to her physical appearance, along with her actions which include talking about other students and hitting other students. In contrast, Mia, who is described as being light skinned, being lanky and having long haired is positioned as smart and also mean. The authors argue that through her positioning in the social network as popular afforded her different positioning socially and mathematically. Mathematically, Mia is able to participate fully whereas Shawna was only able to participate on the margins. This positioning undermined Shawna's opportunity to be seen as 
smart by her peers. A similar finding is found in Jones (2003), where Patti, a Black girl in third grade with similar characteristics as Shawna, is positioned in ways that do not capture her success and competence in mathematics. The two studies described here highlight instances where positioning takes place within a group (e.g. Black learners), across learners (e.g., Black girls and Black boys), and within a subgroup (e.g. Black girls) and each grouping illustrates the complexity of how Black learners are positioned during mathematics instruction. For Black girls in both studies there seems to be a particular way of being and physical characteristics that lead to particular positions. These meanings are problematic, as they inherently constrain opportunities to learn and send messages about what it means to be a doer of mathematics as a Black learner.

Teachers.

As described earlier, few studies actually focus on the work of teaching. Additionally, few studies name the identities of the teacher, describe how those identities might impact their practice, and consider the identities of both the teacher and students in positioning. As mentioned previously, few studies describe the teacher's race, gender, and other background information and connect it to how students are positioned. This may be the case because in some studies the focus is on the positioning of small group interactions, which does not necessarily involve the teacher. There is one study in particular that takes up the role that teachers' identities play in the positioning of a Black learner. Jones (2003) acknowledges how race, gender, and class can play a role in how a Black girl is positioned by her teacher and subsequently her peers. Class is included in this study through the relationship the teachers have with Patti's mom and the relationship that Patti has with her mom. The author points at the tensions that rise when teachers have an idea of what success is, in mathematics class, as well as what it looks like and how students should look to be identified as such.

Despite not taking place in classrooms, Parks (2014) is an example of how teachers' identity, along with issues of power position students by observing students and considering 
their body language. In the studies included in this synthesis we get a sense of how learners are positioned, but mostly consider those positioning by leveraging interactions with a focus on language which describes how learners are positioned. Some studies such as Parks (2014) to a lesser extent, include how students' body language plays a role in the teaching and learning of mathematics. It is important to note that with the inclusion of body language can be dangerous as can be seen from research writ large that Black learners' bodies are often read in problematic ways that have negative consequences.

Although all of the studies here do not take up intersectionality, these studies are useful examples of seeing how intersectionality provides some of the reasons why Black learners are positioned in particular ways, and offer implications for teaching, policy, and research.

\section{Implications}

\section{Teaching}

Despite the lack of studies that attended to teaching, the studies included in the synthesis suggest understanding how both small group work and whole group discussions are structured and the role of the teacher in shaping those group structures is important. In small group work teachers can unknowingly position learners productively or unproductively and those positionings impact how children position one another (Langer-Osuna. 2016). Reform mathematics has placed an emphasis on small group work and provides structures for students to exercise their agency and depend upon their peers. However, in these small groups, inequities can occur. One practical implication of this synthesis is for teachers to manage how they are implicitly and explicitly positioning learners as they not only have implications for the individual, but also for the collective (Gholson and Robinson, 2018).

Although teachers position students, both teachers and students co-construct classroom culture, which includes norms, and necessarily impacts how students are positioned and who is positioned, and by whom. Based upon the studies included in the synthesis we see that part of this issue is the role of power and influence from both the teacher and students, as well as 
teacher responsibility. As concluded in several studies, we see the power and agency students have and how their power and agency can contribute to the development of inequitable classrooms. Given these findings it seems reasonable to think about the role of the teacher and how teachers can intervene on power and social dynamics that take place in classrooms.

For teachers to do this work, it necessarily requires teachers addressing their beliefs around race, gender, and class and how that impacts the positioning of students in classrooms. As in the example of Patti, how the teachers perceived who can be successful in mathematics and what that looks like narrowed the opportunities that Patti had to see herself and be seen as successful in mathematics. Collectively, the findings in the synthesis support the lack of positioning studies that examine the work of teaching as outlined in Ball and Forzani (2009). We would also add that the findings in this synthesis suggests that positioning is a key component of the work of teaching.

\section{Policy}

There are three policy implications of this synthesis worth highlighting. The first implication is providing teachers with extended and frequent professional development around ideas of race, class, and gender identities. As indicated in the findings of some of the studies included in this synthesis the identities of teachers matter and are connected to teachers' practice. Some research has suggested the need for teachers to notice the strengths of students using professional development, also finding opportunities for teachers to think about how their own biases intersect with how they position students and teach mathematics. Given the likelihood that teachers are teaching across difference, that is, teachers are teaching students that have different social identities from them, supporting teachers in seeing how these differences positively and negatively seem prudent.

A second implication of this synthesis is the need to capture moment-to momentinteractions of lessons over time. In this synthesis we saw both peers and teachers position students in productive and unproductive ways. With this in mind there needs to be a 
requirement for teachers to examine how students are being positioned over time. Students' positioning does not occur in a vacuum; rather each position is a cumulation of positionings over time. Said another way, if a student is only positioned as competent consistently, then over time the student may seem to be seen by themselves and peers as competent. In contrast if a student is positioned as slow in math then over time that may come to see themselves as slow and others see them as slow. Therefore, having a tool that allows teachers to see these different positionings of students would allow teachers to think about how to reinforce productive positionings and intervene on unproductive positionings. One tool that might be useful is the Equity Quantified in Participation (EQUIP). EQUIP, developed by Reinholz and Shah (2018) as an observation tool that allows teachers to track which students got to talk during whole-group discussions, for how long, and how those students participate during whole-group discussions. This tool and similar tools could be very useful for teachers as it captures data that they may not normally have. Having data such as what EQUIP produces connects directly with the third implication of this synthesis, which is teachers having opportunities to improve upon their own practice.

A third implication of this synthesis is a need for teachers to have the opportunity and training to study and improve their own practice. Often the opportunities teachers have to improve practice comes from professional development and instructional coaching provided by their respective school and school district. However, with tools described above, there are also opportunities for teachers to learn from their own practice. Being able to self-assess and consider alternative routines, participant structures, and moves that could productively position Black learners is important considering the power and responsibility teachers have. It is also important because students are positioned every day and these positions have consequences for their engagement and opportunities to learn. Therefore, being able to both keep track of and recognize patterns in one's own practice, but also being able to improve upon one's own practice is important. 


\section{Research}

There is a dearth of studies at the middle school level. As shown in table one, only two focused on middle school, with the rest of the studies focusing on elementary and secondary. This could be attributed to variance in what is considered middle school. In some cases, middle school is considered seventh and eighth grades only, whereas in other cases, middle school also includes sixth grade. The absence of studies at the middle school level could also be attributed to the focus of this synthesis, namely that we focus on Black learners and their positioning in mathematics. Regardless, the findings from the synthesis, which primarily focus on elementary and secondary, suggest the potential value of studying this topic in middle school.

One emphasis that seems to be important are studying contexts in which both teachers and students have a variety of identities. This point is particularly salient as the synthesis suggests that there is heterogeneity in perceived homogeneous spaces. Studying contexts that provide the opportunities to consider different intersections of identity and power relations can provide a more nuanced understanding of how and why Black learners are positioned in mathematics classrooms in particular ways. Additionally, it also seems relevant to investigate student interactions during whole-group, small-group, and independent work. A number of studies in this synthesis focused on small-group work or dyads. It would be interesting to see how students are positioned during whole-group discussions and one-on-one interactions with teachers. Another point worth considering is the curriculum and participation structure. Looking across the studies, it was not always clear the relationship between mathematical tasks students worked on and participation structure. In the studies that did such as Hand (2010) we see although the tasks were rigorous, the participation structures were very narrow, which limited student's opportunity to engage in the content in rigorous ways.

\section{Conclusion}


The purpose of this synthesis was to investigate how Black learners are positioned in mathematics classrooms. Focusing on positioning afforded us the opportunity to see how learners are positioned moment-to-moment. Seeing how Black learners are positioned momentto-moment is useful, because we see how Black learners are positioned and by whom. Due to the granular size there are takeaways for the role of tasks, participation structures, identities, and potential ways for teachers to reinforce productive positionings of Black learners and disrupt unproductive positionings for Black learners. In this synthesis we found that Black learners are likely to be positioned in unproductive ways by their peers and by their teachers. Even when students are positioned in productive ways, there are consequences for that student and their peers. Despite knowing both the likelihood that Black learners are positioned unproductively, teaching is one path that disrupts this pattern as evidenced in the synthesis. However, doing this work also includes attending to the intersectionality that teachers bring to classrooms and the students they teach. This synthesis does not just highlight the unproductive and productive positioning of Black learners, but it also highlights the within group differences, which makes our understanding of positioning more nuanced. Although all of the studies in the synthesis included Black learners, during interactions we see how different identities such as gender and class are relevant and how those identities have implications for agency and power in mathematics classroom. Despite seeing the role of intersectionality for students, in the studies included, it was challenging to get a sense of the different identities of the teacher. However, when available we could see how ideas around race, gender, and class impact teachers' practice. Although this synthesis contained only 12 studies, it does suggest there are several implications for practice, policy and future research. 


\section{References}

Ball, D.L., \& Forzani, F. M. (2009). The work of teaching and the challenge for teacher education. Journal of teacher education, 60(5), 497-511.

Berry, R., \& Thunder, K. (2013). The promise of qualitative metasynthesis: Mathematics experiences of black learners. Journal of Mathematics Education at Teachers College, 3(2).

Bishop, J. P. (2012). "She's always been the smart one. I've always been the dumb one": Identities in the mathematics classroom. Journal for Research in Mathematics Education, 43(1), 34-74

Crenshaw, K. (1989). Demarginalizing the intersection of race and sex: A black feminist critique of antidiscrimination doctrine, feminist theory and antiracist politics. u. Chi. Legal f., 139.

Davies, B., \& Harré, R. (1990). Positioning: The discursive production of selves. Journal for the theory of social behaviour, 20(1), 43-63.

Esmonde, I., \& Langer-Osuna, J. M. (2013). Power in numbers: Student participation in mathematical discussions in heterogeneous spaces. Journal for Research in Mathematics Education, 44(1), 288-315.

Gholson, M., \& Martin, D. B. (2014). Smart girls, Black girls, mean girls, and bullies: At the intersection of identities and the mediating role of young girls' social network in mathematical communities of practice. Journal of Education, 194(1), 19-33.

Gholson, M. L., \& Robinson, D. D. (2019). Restoring mathematics identities of Black learners: A curricular approach. Theory Into Practice, 58(4), 347-358.

Gholson, M. L., \& Wilkes, C. E. (2017). (Mis) taken identities: Reclaiming identities of the "collective Black" in mathematics education research through an exercise in Black specificity. Review of Research in Education, 41(1), 228-252.

Grant, M. R., Crompton, H., \& Ford, D. J. (2015). Black male students and the Algebra Project: Mathematics identity as participation. Journal of Urban Mathematics Education, 8(2). 
Gutiérrez, R. (2013). The sociopolitical turn in mathematics education. Journal for Research in Mathematics Education, 44(1), 37-68.

Hand, V. M. (2010). The co-construction of opposition in a low-track mathematics classroom. American Educational Research Journal, 47(1), 97-132.

Jackson, K. J. (2010). The social construction of youth and mathematics: The case of a fifthgrade classroom. In Mathematics teaching, learning, and liberation in the lives of Black children (pp. 185-209). Routledge.

Jones, S. (2003). Identities of race, class, and gender inside and outside the math classroom: A girls' math club as a hybrid possibility. Feminist Teacher, 220-233.

Langer-Osuna, J. M. (2011). How brianna became bossy and kofi came out smart: Understanding the trajectories of identity and engagement for two group leaders in a project-based mathematics classroom. Canadian Journal of Science, Mathematics and Technology Education, 11(3), 207-225.

Langer-Osuna, J. M. (2016). The social construction of authority among peers and its implications for collaborative mathematics problem solving. Mathematical Thinking and Learning, 18(2), 107-124.

Langer-Osuna, J. M., \& Esmonde, I. (2017). Identity in research on mathematics education. Compendium for research in mathematics education, 637-648.

Lerman, S. (2000). The social turn in mathematics education research. Multiple perspectives on mathematics teaching and learning, 19-44.

Nasir, N. I. S., \& Shah, N. (2011). On defense: African american males making sense of racialized narratives in mathematics education. Journal of African American Males in Education, 2(1), 24-45.

Nzuki, F. M. (2010). Exploring the nexus of african american students' identity and mathematics achievement. Journal of Urban Mathematics Education, 3(2), 77-115. 
Parks, A. N., \& Schmeichel, M. (2014). Children, mathematics, and videotape: Using multimodal analysis to bring bodies into early childhood assessment interviews. American Educational Research Journal, 51(3), 505-537.

Reinholz, D. L., \& Shah, N. (2018). Equity analytics: A methodological approach for quantifying participation patterns in mathematics classroom discourse. Journal for Research in Mathematics Education, 49(2), 140-177.

Turner, E., Dominguez, H., Maldonado, L., \& Empson, S. (2013). English learners' participation in mathematical discussion: Shifting positionings and dynamic identities. Journal for Research in Mathematics Education, 44(1), 199-234.

Wood, M. B. (2013). Mathematical micro-identities: Moment-to-moment positioning and learning in a fourth-grade classroom. Journal for Research in Mathematics Education, 44(5), 775808. 